\title{
El secretario del obispo: poesía, chistes y secreto episcopal en los escritos relativos al gobierno de la diócesis de Santiago de Chile en la segunda mitad del siglo XVIII
}

The Bishop's Secretary: Poetry, Jokes, and Secret in Writings Concerning the Government of the Dioceses of Santiago de Chile in the Second Half of Eighteenth Century*

DOI: https://doi.org/IO.22380/20274688.11 47

Recibido: 26 de enero del 2020

Aprobado: 12 de marzo del 2020
BERNARDA URREJOLA**

Universidad de Chile

bernarda.urrejola@uchile.cl

\section{R E S U M E N}

En este trabajo me acerco a la figura invisible del secretario del obispo, un miembro muy importante de la llamada "familia" del prelado, lo que constituía su círculo más

* Agradezco a Conicyt por permitirme investigar mediante el proyecto Fondecyt regular in 71070 , del que soy investigadora responsable (2017-2020). En el marco de este proyecto pude realizar dos estancias de investigación en México, cuyo financiamiento fue complementado por la Universidad de Chile. La primera estancia, en el 20r8, obtuvo ayuda de viajes de la Facultad de Filosofía y Humanidades, y la segunda, en el 2019, contó con el apoyo de la Vicerrectoría de Investigación y Desarrollo. Agradezco el constante apoyo de Francisco Burdiles en el trabajo de archivo.

** Licenciada y magíster en Literatura de la Universidad de Chile, maestra y doctora en Historia del Colegio de México. Profesora del Departamento de Literatura de la Universidad de Chile, donde imparte clases de literatura colonial y teoría literaria desde el 2003. https://orcid.org/0000-0002-5953-853X. 
íntimo, de máxima confianza. El secretario, en efecto, era el encargado de guardar el "secreto" del obispo, es decir, los papeles más importantes para el gobierno de la diócesis, por lo que su función resultaba fundamental y estaba reglamentada por las disposiciones de Trento. El secretario actuaba muchas veces como notario o firmaba las cartas del obispo, pero nada se dice de la edición que hacía de textos eclesiásticos importantes que el obispo solo había escrito en borrador. Aquí se estudian al menos dos ejemplos en que la mano del secretario se desliza y puede ser identificada. Más allá de un nombre, es una "función" textual que añade, edita y adorna los dichos del obispo, para desaparecer tras él casi sin dejar huella.

Palabras clave: obispo de Santiago de Chile, Manuel de Alday, secretario del obispo, diócesis, siglo XVIII

\section{$\begin{array}{llllllll}\mathbf{A} & \mathbf{B} & \mathbf{S} & \mathbf{T} & \mathbf{R} & \mathbf{A} & \mathbf{C} & \mathbf{T}\end{array}$}

This investigation approaches the invisible figure corresponding to the secretary of the Bishop, a crucial member of the so called "family" of the prelate, considered as part of the intimate circle and a trustworthy figure. The secretary was the person in charge of keeping the Bishop's "secrets", which include the most important documents of the dioceses. Therefore, his role was fundamental and was regulated by the requirements of the Trent. The secretary performed several times as a notary or signed the Bishop's letters, but nothing has been said about the editing he carried out of important ecclesiastical texts that the Bishop had only just drafted. Here are presented at least two examples that clearly show the manifestation of the secretary's hand. More than a name, the secretary will be a text function through which this character will add, edit and garnish the sayings of the Bishop in order to disappear behind his image, almost without any trace.

Keywords: bishop, Manuel de Alday, secretary, dioceses, Santiago de Chile, Eighteenth century

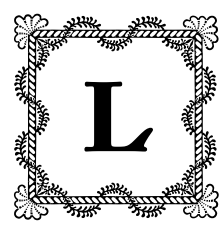

os manuales para formar secretarios, típicos de los siglos XVI y XVII, así como las investigaciones sobre esta figura histórica, suelen enfocarse en el mundo secular: se estudia, por ejemplo, la labor de los secretarios de la corte de Madrid o de aquellos que sirvieron a importantes señores de la época ${ }^{\mathrm{I}}$. En esa línea, se suele

I Para mayor información sobre estudios acerca de los secretarios de Estado de la monarquía, véase López-Cordón; Gómez. 
identificar al secretario con el escribiente, quien, como el nombre lo indica, se encargaba fundamentalmente de escribir las cartas de su señor, tarea muy necesaria en un mundo en el que no todos manejaban las artes de la escritura, por más que supieran leer. También se identifica al secretario con el escribano público, ministro de fe de documentos legales. Sin embargo, escribano, escribiente y secretario no eran lo mismo (Gómez); por lo demás, sus funciones fueron cambiando a lo largo de la historia de la monarquía, particularmente debido al cambio de estilo de gobierno que se produjo entre Austrias y Borbones (García). Durante el Siglo de Oro hispánico, la figura del secretario cobró gran relevancia por el auge de la vida en la corte y el crecimiento de la burocracia. Sin ir más lejos, el propio Lope de Vega fue secretario de importantes figuras políticas de la época, como el duque de Alba, e incluso transformó al secretario en personaje de varias de sus obras (Del Río). El secretario, en todo el espectro de su desempeño, era una figura crucial para la maquinaria política de la época, pues no solo manejaba la documentación que llegaba a su señor, sino que podía influir en las decisiones que se tomaban a partir de los documentos que pasaban por sus manos o aquellos que producía su pluma. De ahí que los manuales centrados en el arte y el estilo de escribir cartas, que surgieron particularmente en la época de Felipe II, se pensaran para formar buenos funcionarios para la Corona, diestros en el manejo de los papeles del soberano y conscientes de su lugar en el organigrama de la monarquía (Serrano).

En su Manual de escribientes, de mediados del siglo xvi, Torquemada señalaba que una de las bases del oficio de escribiente era el manejo de la retórica, lo que podía llegar a provocar tensiones entre el secretario y su señor, porque muchas veces el secretario tenía más erudición que el mismo amo (Rodríguez). No obstante su alta formación letrada, el secretario debía ser el doble invisible de su señor, incluso disimular su saber para poder imitarlo mejor en su forma de hablar y de escribir. En suma, se trataba de un juego de espejos en el cual el secretario debía tomar el lugar de su señor en la escritura, pero desaparecer en la autoría y disimular sus características propias detrás de las de su amo. La Dirección de secretarios de señores y las materias y cuidados y obligaciones que les tocan, de Gabriel Pérez del Barrio (I6I3), fue el primero de los denominados "manuales de secretarios", obras con las que se pretendía formar a los secretarios de la época, con el objetivo además de lograr para ellos una mayor consideración social y privilegios en la Corte (Serrano). Miguel de Cervantes escribió uno de los poemas laudatorios al autor del manual, quien a su vez era secretario, destacando su gran capacidad para levantar la pluma del suelo y elevarla al cielo, 
emulando a Demóstenes y a Cicerón, con lo que sugería que una escritura que por naturaleza merecía el suelo, gracias a las artes del escribano alcanzaba vuelos insospechados (Pérez). El trabajo del secretario, entonces, constituía el "nervio" de las estructuras en las que se desempeñaba, figura fundamental y con un poder que muchas veces resulta difícil de aquilatar ${ }^{2}$.

De todas las características que se destacan como imprescindibles para los secretarios de este tipo, el primer lugar lo tiene la confianza que debe merecerle a su señor — pues se asemejan a los "validos" o favoritos del rey-; no es menos importante verificar la influencia de los lazos de parentesco en la selección de los candidatos. En suma, como se puede inferir, los secretarios podían tener gran influencia en el ámbito de la Corona, por el manejo de papeles secretos cruciales para la monarquía (López-Cordón).

\section{El secretario del obispo}

Si el conjunto de estudios disponibles sobre los secretarios se centra en los escribientes o escribanos seculares, un tipo de secretario muy distinto, del que poco se habla, es el secretario del obispo, grupo que permanece invisibilizado en la historia eclesiástica, pese a su lugar extremadamente relevante en la mantención del "secreto" episcopal, esto es, en la conservación del orden de los papeles del obispo y en el equilibrio entre la aparición pública y la vida privada del prelado. El secretario del obispo tenía varias de las características de los secretarios de Estado o de despacho e incluso se acerca mucho al escribano en algunas ocasiones, por lo que llama la atención que su participación haya quedado disimulada en la historia.

Para estudiar los rastros de este tipo de secretario eclesiástico tomaré el caso del obispo Manuel de Alday y Aspée, quien ocupó la silla episcopal de Santiago de Chile entre 1755 y 1788 . De todo el periodo en que gobernó la diócesis, pretendo centrarme en el tiempo comprendido entre 1757 y I772, fechas marcadas por dos hitos: su primera visita episcopal y su asistencia al VI Concilio provincial de Lima. De cada uno de estos eventos quedaron textos que permiten

2 Un compendio de estudios sobre la figura del secretario asociado al escribano, o incluso al notario, se titula precisamente El nervio de la República, y se trata de un acercamiento desde el ámbito jurídico, que no es el que nos interesa en este trabajo, por más que el secretario del obispo podía funcionar como notario en situaciones específicas. 
identificar rastros de un secretario: el primero, la relación o diario de registro de la visita episcopal que realizó por el norte de Chile en I757 y, el segundo, la oración predicada por Alday en la apertura del VI Concilio limense de 1772 , publicada luego en Lima. No estudiaré aquí una biografía en particular, pues mi interés no se centra en una persona, sino en cierta "función”, como señalaría Foucault ${ }^{3}$, que fue desempeñada por distintas personas en el tiempo y que puede ser rastreada en las huellas de plumas que aparecen y desaparecen, tanto en los escritos destinados a ser publicados bajo la autoría oficial del superior eclesiástico, como en textos cuya finalidad no era la publicación, sino servir de materia prima para informes oficiales. Mediante este estudio, basado en huellas textuales y cruce de documentos, pretendo contribuir a la apertura de un campo prácticamente inexplorado en las investigaciones sobre las gestiones episcopales, que abreva del análisis del discurso y que permite dar una densidad distinta a la concepción de los obispos que brindan los episcopologios tradicionales, en los que se asume que las gestiones de los obispos y sus escritos le pertenecen del todo al prelado. No obstante, el estudio de los rastros de los secretarios permite ver que quizá ellos ańadieron o quitaron mucho más de lo que pudiéramos suponer. Veamos a continuación su inserción en el mundo de los prelados.

El secretario del obispo formaba parte de la llamada "familia" del prelado, es decir, aquel conjunto de personas colocadas bajo su jurisdicción personal, "desde sus colaboradores oficiales, vicarios, visitadores y secretarios, hasta sus criados, mayordomos y pajes" (Dedieu 203). La familia del obispo convivía con él y componía su "casa": era un grupo que podía ser bastante heterogéneo y que incluía "desde parientes sanguíneos hasta clientes y protegidos, pasando por sirvientes y numerosos clérigos" (Irigoyen 574). Este "elenco de servidores" (Artola) se dividía en grupos según el nivel de cercanía respecto del obispo, y funcionaba, siguiendo a Jean-Pierre Dedieu, como una "burbuja protectora" (205) frente a posibles amenazas externas, lo que beneficiaba tanto al obispo como a los propios "familiares". En ese sentido, el sustento que el obispo brindaba a sus subordinados significaba en muchos casos para ellos el acceso a un “capital relacional y simbólico" (Artola) que les otorgaba beneficios dentro del

3 Sobre el autor como "función", más que como persona biográfica, véase el ya clásico trabajo de Michel Foucault “QQué es un autor?”, que permite entender al “autor” como un lugar ocupado por múltiples voces y no un sujeto en particular. Esta perspectiva será la que se siga en este trabajo, a diferencia de los estudios centrados en el rol social, histórico o jurídico de determinados secretarios, acercamiento que ha caracterizado a los estudios hispánicos sobre los secretarios de Estado o de despacho. 
sistema eclesiástico; viceversa, el obispo podía establecer con sus protegidos una relación formativa en la que los preparaba para una carrera eclesiástica que pudiera posteriormente servirle a él mismo (Irigoyen 577).

Al respecto, considerando la gran cercanía e intimidad con los prelados, el Concilio de Trento puso una especial atención a la familia del obispo, a cuyos miembros llama "ministros de los ministros de Dios". En la sesión II (De modo vivendi) exhortaba a los prelados a ser "muy atentos al gobierno de sus casas", por lo que debían instruir a sus familiares para que no fueran "pendencieros, vinosos, desenvueltos, ambiciosos, soberbios, blasfemos, ni dados a deleites, huyan, en fin, de los vicios y abracen las virtudes, manifestando en sus vestidos aliño y demás actos la honestidad y modestia correspondiente a los ministros de los ministros de Dios" (Trento sesión II).

Muchas veces, las órdenes del Concilio fueron concretadas en manuales o tratados específicos sobre determinados temas, como el que escribió el célebre y prolífico obispo-virrey Juan de Palafox y Mendoza, quien describió en detalle a los miembros de la familia del obispo en su tratado Direcciones pastorales o instrucción de la forma con que se ha de gobernar el Prelado en orden a Dios, a si mismo, a su familia y súbditos (I646). Inspirado en Carlos Borromeo, Palafox clasifica en cuatro grupos a los criados de los obispos, vinculados con la "casa" episcopal: los relacionados con el culto divino, los de hacienda, los domésticos y los menores ${ }^{4}$. Los relacionados con el culto divino eran, fundamentalmente, el teólogo de cámara, el confesor — que podía ser el mismo teólogo de cámara-, los sacristanes, los mozos de la sacristía y el limosnero. Los criados de "hacienda" eran el tesorero del obispado y el contador. Los oficios domésticos y menores, que son los que más interesan en este trabajo, "miran al gobierno y asistencia de la persona del obispo" (Palafox 74) ${ }^{5}$. Entre los domésticos, el cargo principal era el del mayordomo, pues tenía la responsabilidad de toda la familia del obispo,

Hay distintas formas de clasificar a los grupos que conformaban la familia del obispo; aquí prefiero la de Palafox, pues este obispo me parece más cercano a la época y al contexto de Manuel de Alday. Jean-Pierre Dedieu, por ejemplo, ordena los mismos cuatro grupos de modo diferente: primero los ayudantes de cámara, los lacayos, los cocineros y los ayudantes de cocineros; luego los colaboradores en el gobierno de la diócesis, es decir, los cargos administrativos de confianza: el confesor personal, el secretario, el provisor, el abogado de cámara — asesor jurídico del obispo-y el fiscal del tribunal episcopal. El tercer grupo, según Dedieu, estaba integrado por los oficiales de la casa: el mayordomo, el tesorero y a veces el maestro de pajes. El último grupo sería el de los pajes, a quienes el obispo alimentaba y en ocasiones les daba estudios y carrera. Se puede apreciar que esta clasificación no coincide exactamente con la del obispo de Puebla. 
así como la administración de la casa y la atención de los huéspedes (Latasa 215). El oficio que seguía en importancia era el del secretario; luego venían el camarero, los capellanes, el maestresala, el veedor, el maestro de pajes, los pajes y el caballerizo. Los oficios menores los cumplían el repostero, el despensero, el portero, el lacayo, el cocinero, el cochero y el resto de los criados de la familia, a quienes Palafox llama "criados de los criados de casa" (Palafox Io8). Es de suponer que en la lejana capitanía general de Chile el número de familiares del obispo fuera bastante más reducido de lo que consigna Palafox. En efecto, la "familia" que acompañaba al obispo Alday en sus visitas episcopales estaba compuesta por un número muy reducido de personas, como veremos.

Ahondemos en el oficio doméstico del secretario. Palafox consideraba su cargo como "el más reservado de la casa", por ser "la mano por donde se guía y gobierna todo, oficio de particulares preminencias y de singular confianza" (Palafox 78), pues a través de él se veían asuntos que podían llegar a ser muy delicados. En ese sentido y por su relevancia estratégica, Palafox aconsejaba escoger para este cargo a un "sacerdote de juicio despierto y claro, de virtud conocida y condición apacible y modesta, inclinado a silencio y secreto, a quien hará luego el Obispo notario, por que pueda estar hábil para lo que se ofreciere" (Palafox 78). En efecto, uno de los secretarios de quien hablaremos en este trabajo actuó como notario con ocasión del sínodo diocesano que convocó el obispo en ${ }^{7} 763$, aunque habrá que ver si ambos secretarios cumplían con las demás condiciones que sugería Palafox.

En cuanto al espacio de trabajo, la importancia de los papeles que revisaba el secretario ameritaba que la casa del obispo contara con una oficina especial para él, a la que solo podían entrar, además del propio secretario, el obispo y el escribano. Esta oficina debía contar con dos sectores, separados por una celosía: una zona destinada a recibir personas y otra para trabajar, a la que no podían ingresar personas externas (Latasa 215). El secretario "no ha de dormir, comer ni cenar" en la secretaría, "sino que solo ha de acudir allí al ejercicio de su ministerio" (Palafox 79). Según el manual del prelado, "toda esta diligencia y cuidado debe tener para conservar el secreto, que es la substancia total de su oficio y la que le acredita y autoriza y da el nombre de secretario" (Palafox 79). En efecto, el secretario debía guardar los papeles del gobierno del obispado y dar instrucciones sobre el modo de llevar el archivo episcopal (Latasa 215). Por su alta responsabilidad, no tenía autorización para salir sin avisar al obispo, como tampoco podía sacar papeles de la secretaría, ni menos hacer copia de documentos sin licencia del prelado. En cuanto a su rutina, Palafox la describe así: 
Todas las mañanas, en saliendo el obispo de su retrete o Oratorio, ha de acudir a recibir el Secretario las órdenes que le diere y copiarlas y reducirlas a billetes y enviarlas; porque con estas se ha de obrar y ejecutar aquel día y los siguientes todo lo conveniente al gobierno. Y el Secretario solo ha de ser por cuya mano se da a todo forma y dirección y el que tendrá sabido lo más reservado y secreto y el que intervendrá en las juntas con los que el obispo señalare y el que guardará sus secretos y órdenes. (Palafox 80)

Sobre la paga, Palafox indicaba que el secretario no debía pedir más derechos de los que se establecían para su cargo en el Concilio de Trento. Y sobre el trato que debía tener el obispo hacia él, Palafox agregaba que, tal como al resto de los familiares, "el obispo unas veces los ha de tratar como a criados, cuando representa su dignidad: otras como a compañeros, esto es en sus trabajos; otras como maestro, esto es en su ejemplo; otras como padre, en tolerar sus imperfecciones" (cit. en Latasa 226).

Sobre las tareas del secretario y la forma de guardar los papeles, Palafox consideraba que el secretario debía procurar lo siguiente:

I. Tener un libro en que anotara todas las iglesias, las parroquias, los conventos, los hospitales y las obras pías del obispado y de los bienes raíces y muebles que hubiera en ellos.

2. Llevar una lista de los clérigos del obispado, su calidad, las personas y las costumbres, "con los apuntamientos que hiciere el obispo en su visita" (Palafox 80). La importancia de este libro es clara: "este libro ha de tener cerrado en la Secretaría, de manera que no lo vean los oficiales, si ya el obispo (que será lo más cierto) no lo tuviere consigo, porque ha de ser el manual de su gobierno" (Palafox 80).

3. Llevar una lista de todas las órdenes, los edictos, las cartas pastorales y los avisos, así como su resolución.

4. Hacer una copia de todas las órdenes dadas por el obispo, para que se supiera cuándo y a quién se había enviado cada orden y cuándo estas habían sido recibidas.

5. Tener plena claridad de la correspondencia del obispo, las cartas que escribía y recibía y reducirlas a cuadernos. Cada año compilar dichos cuadernos en libros y dejar copia en la secretaría de todo lo escrito "y cuanto fuere necesario para conservar y guardar hasta la menor noticia” (Palafox 8I). 
Como se puede apreciar, el secretario llevaba el catálogo de todo el obispado, de sus habitantes clérigos y seglares, de sus edificaciones y propiedades. Recién en el punto 5 se destaca el manejo de las cartas como labor del secretario, lo que nos habla del lugar que tenía esta labor dentro del conjunto de tareas a su cargo. El secretario del obispo, como se puede apreciar, era mucho más que un "escribiente" al estilo de los personajes de Lope de Vega que escribían cartas para sus señores y mucho más que el "escribano" encargado de legitimar documentos como ministro de fe, tarea que ni siquiera es enumerada por Palafox en la cita anterior. Es cierto que el secretario del obispo podía funcionar como notario, pero ello sucedía solo esporádicamente, por ejemplo con motivo de la celebración de los sínodos diocesanos, oportunidad en la cual el secretario hacía las veces de ministro de fe que certificaba que lo que se había transcrito en el documento oficial correspondía íntegramente a lo tratado en las sesiones sinodales.

Más allá de sus atribuciones jurídicas específicas para tal o cual ocasión, Palafox destaca la importancia de la firma del secretario, pues por sus manos pasaba todo el secreto administrativo: cada papel rubricado por él se transformaba en oficial y auténtico, con una legalidad tal que el secretario se asemejaba en importancia al juez provisor o vicario del obispo:

[...] porque habiendo de gobernar el obispo precisamente con cartas, órdenes, edictos y correspondencias, cualquiera breve ausencia puede hacer grave daño a lo público y así, o ha de estar el Secretario en su oficio, o con la persona del Obispo o en cualquiera otra parte que esté, que no sea muy precisa, puede justamente hacérsele cargo. (Palafox 80)

Incluso el secretario debía tener espacios o escritorios cerrados para guardar todos los secretos del obispo, espacios "de los cuales él solo tenga la llave" (Palafox 80), pues llevaba los libros de registro de las órdenes, las licencias para misas, predicación y confesión, así como los nombramientos en curatos, y autorizaba en suma todos los documentos episcopales (Enríquez I50). En ese sentido, su vínculo con los documentos era muy cercano; de ahí que Palafox considerara muy importante que tuviera buena ortografía:

Aunque no es lo substancial de las buenas partes del Secretario el escribir buena letra, todavía se le debe tener por una circunstancia muy considerable y será bien que cuide mucho de eso, a lo menos muy bastantemente clara y con buena ortografía y distinción. El estilo llano y fácil, y pocas veces o nunca introduzca en sus cartas, ordinarias frases, ni palabras muy particulares o poco usadas, echando mano de los conceptos 
más claros y los argumentos más precisos de cada cosa, procurando escusar la superfluidad y repetición de razones y palabras. (Palafox 79)

La relevancia de la buena caligrafía, la ortografía y el estilo llano se relacionaba con el hecho de que muchos de los papeles escritos por el secretario eran presentados a nombre del obispo, por lo que la imagen del prelado estaba en juego en la escritura de su secretario, cuyo nombre no siempre aparecía en los documentos. Por eso, no es de extrañar que para Palafox fuera importante que el secretario escribiera "excelentemente". Veremos en qué medida cumplen estas disposiciones los secretarios de Alday, sobre todo si de uno de ellos dice Carlos Silva Cotapos: "su pluma era fácil y su estilo jovial. Gustábale también versificar festivamente, y lo hacía con cualquier pretexto y con el deplorable gusto que el padre Isla fustigó en su fray Gerundio" (Silva 26). Veamos entonces las huellas textuales de dos secretarios de obispo, a continuación.

\section{El primer secretario de Alday (1755-1763): el "secretario-poeta"}

Como todo obispo, Alday tuvo varios secretarios durante su periodo, incluso entre 178I y 1785 le dio esta función a su propio sobrino, José Santiago Rodríguez Zorrilla, quien es conocido por haber sido nombrado obispo en I8I4 por el Consejo de Regencia (Enríquez 358). Esto nos habla, sin duda, de las redes clientelares en el interior de las carreas eclesiásticas, lo que ha sido ampliamente estudiado, por ejemplo, por el historiador mexicano Rodolfo Aguirre Salvador.

$\mathrm{Al}$ ascender a obispo en $\mathbf{1 7 5 5}$, Alday nombró como primer secretario de cámara al presbítero doctor Joseph Gregorio Cabrera (Silva 24), quien había sido secretario del anterior obispo, Juan González Melgarejo. Cabrera no siempre firmaba los documentos que escribía para Alday, pero lo más probable es que haya estado detrás del diario de la primera visita episcopal (1757), que nos interesa aquí como primera huella relevante de la figura del secretario del obispo, cargo que Cabrera mantuvo hasta 1763.

Precisamente la fecha de 1763 es importante porque ese año Alday convocó al V Sínodo Diocesano de Santiago, y en el texto, impreso en Lima, aparece ya el nombre del nuevo secretario firmante: Blas de Vera, de quien hablaremos en la segunda parte de este trabajo, lo que quiere decir que ya en 1763 el primer secretario había dejado su lugar al segundo. En efecto, en el sínodo de 1763 
Blas de Vera firmaba como secretario de cámara y notario, mientras que Joseph Gregorio Cabrera, el primer secretario, aparecía como juez para zanjar posibles diferencias (Alday, Synodo). Esto muestra que las funciones podían cambiar y que un clérigo que había sido secretario del obispo podía luego seguir su propia carrera eclesiástica, como hizo el sobrino de Alday antes mencionado y como también sucedió con Joseph Cabrera, según consigna Lucrecia Enríquez: Cabrera, José Gregorio. Fichoz No ioor25. 1729, nacimiento en San Juan (Paraguay). 1745, familiar de Juan González de Melgarejo, obispo de Santiago de Chile. 1752*, ordenación sacerdotal en Santiago de Chile. 1752, secretario de cámara, confesor y capellán de Juan González de Melgarejo, obispo de Santiago de Chile. I754, secretario de cámara, confesor y capellán de Manuel de Alday, obispo de Santiago de Chile. 1756, doctor en teología por la Universidad de San Felipe. 1767, cura del Sagrario. 1774, racionero de la catedral de Santiago de Chile. 1782, canónigo. 1792, rector de la Universidad de San Felipe. 1798, tesorero. I798, muerte. (35I)

Como se puede apreciar, el secretario de cámara del obispo podía ser a su vez, como en este caso, confesor y capellán, lo que habla de una gran intimidad con el obispo, pues no solo manejaba el secreto de sus documentos episcopales, sino el propio secreto de su alma. Esto debió de darle bastante poder al secretario, sin duda. A juzgar por la información que se conoce, Joseph Cabrera tendría unos veintiocho años cuando acompañó al obispo en su primera visita episcopal, en I757. Ya firmaba documentos para Alday desde antes, por ejemplo la carta en que, como obispo electo y aun sin recibir oficialmente el cargo, el 4 de octubre de 1754, Alday solicitó que el corazón del recientemente fallecido padre jesuita Ignacio García, su confesor hasta entonces, se depositara en una cajita en el monasterio de Santa Rosa. Esa carta cierra "Por mandato de su señoría ilustrísima, el obispo, mi señor. Joseph Cabrera, secretario". Recordemos que desde 1753 Alday había sido nombrado obispo por "ruego y encargo" del rey y desde entonces funcionaba, en la práctica, como el gobernador de la diócesis, de modo tal que en $\mathbf{7 5 5}$, luego de tomar oficialmente posesión de su cargo, confirmó también a Joseph Cabrera como secretario oficial, lo que no ella y gobernador de su obispado, del Consejo de S.M.\&” (Eyzaguirre 232-234). 
impidió, como se desprende de la carta de 1754, que desde antes de esa fecha ya trabajaran juntos.

Como se sabe, todo obispo tenía por obligación realizar la visita de su obispado e informar de lo que encontrara al rey y, en algunos casos, al papa. Apenas asumió su cargo, Alday decidió iniciar la visita de su obispado, que terminaría con el llamado a sínodo diocesano en $\mathbf{1 7 6 3}$. El diario de la primera visita episcopal del que trataremos a continuación fue escrito, si acogemos la afirmación contenida en el propio texto, en 1757, mismo año en que comenzó Alday a visitar el norte del territorio. Si bien el documento no está firmado, hay muchos indicios de que fue escrito por el secretario. La caligrafía no es de Alday, a diferencia de múltiples documentos autógrafos en los cuales el obispo hacía anotaciones de sus viajes o de reuniones ${ }^{7}$; por lo demás, consta que efectivamente en 1757 Joseph Cabrera era el secretario, por un auto enviado el 3 de marzo de ese año al gobernador y capitán general del reino de Chile y presidente de la Real Audiencia, Manuel de Amat, contra las fiestas de campańa o ramadas, impreso junto al sínodo de 1764 y firmado "por mandado de su Señoría Ilustrísima, el Obispo, mi Señor. Doctor Joseph Cabrera, Secretario” (Alday, Synodo 156).

El documento de la visita, que se conserva manuscrito en el Archivo Nacional Histórico de Chile, permaneció inédito por 150 años, hasta que apareció impreso por primera vez en la Revista Católica en I9I3 (tomos Xxix y xxx), con algunas imperfecciones en la transcripción. En el Archivo Nacional ha sido clasificado como Relación del viaje que hizo con su comitiva el Ilustrísimo señor doctor don Manuel de Alday, dignisimo obispo de Santiago de Chile, en la primera visita de su obispado, desde el día 23 de abril de 1757 hasta el día 20 de noviembre del mismo año. Quien escribe se refiere al texto como "relación de viajes" y lo clasifica como "diario", antes de que comience propiamente la narración de la visita. Es interesante reparar en el estilo de la narración, pues la obligación del secretario era simplemente ir registrando las leguas caminadas cada día, el número de confesiones, etcétera; no obstante, inmediatamente llama la atención que este secretario comienza de forma particular su relato:

Vaya de relación a Dios y a la ventura y como es relación de viaje, algunos querrían que fuese a toda carrera y otros, que gastan más lentitud, gustarán que sea paso a paso: por eso, para acomodarme al genio de

7 En el Archivo Nacional Histórico de Chile se conservan múltiples documentos autógrafos de Alday. Véase al respecto la edición crítica de la Alegacía de méritos, autógrafa de Alday, de Urrejola et al. 
los unos y de los otros, va primero en Diario y después en Resumen y aunque no van algunos pasos, los más van insinuados o se dan por entendidos por no molestar con la repitición. Si bien el resumen se lo puede hacer cualquiera, abreviando o acortando cuando le pareciere y por más que sea dilatado el viaje, luego que quiera hacer punto, el letor hallará fácilmente en su mesma pausa la posada. Alguna vez ocurre alguna Musa para celebrar algún paso y divertir las molestias del dilatado camino y mucho más ocurría que celebrar, si no estuviese la Musa, o tan divertida o preocupada. Al fin, empiezo y ahorrando de exordios, vaya como Dios lo depare el Diario (f. I r.). ${ }^{8}$

La "musa" a la que se refiere el narrador aparece en distintos momentos del viaje para hacer versos, generalmente jocosos y que interrumpen la narración. La voz que narra no se identifica claramente, sin embargo, indica quiénes son los acompañantes del obispo:

Sábado, día 23 de abril del año del Señor 1757, salió al alba a la primera visita de la primera parte de su dilatado obispado el ilustrísimo señor doctor don Manuel Alday, meritísimo obispo de Santiago de Chile. En la comitiva, a más del señor secretario, dos pajes y algunos pocos criados de su Ilustrísima, se allegaron dos padres de la Compañía de Jesús por capellanes. (ff. I r.-I v.)

Integraban la comitiva que visitaría la parte norte del obispado de Santiago, como se ve, "el seńor secretario", dos pajes, algunos criados y los dos padres de la Compañía de Jesús que, según el narrador, se "allegaron" como capellanes. Silva Cotapos aseguraba que el narrador era un "jesuita, al parecer catalán” (26), porque incorpora unas coplas en esa lengua. No obstante, el narrador se burla constantemente de los padres jesuitas, lo que dificulta considerarlo uno de ellos. A modo de ejemplo, recuerda que los herejes los llamaban "lebreles de los obispos", aunque al respecto dice que es fructífero "echarles los galgos" a las ovejas descarriadas (f. I v.), con referencia a la predicación que hacían los padres en los dilatados parajes que visitó el obispo, donde iban "los jesuitas, ya gritando, ya confesando" (f. 2 r.).

8 He modernizado la ortografía en algunos casos, como en "viage", "passo", "haser", sin alterar el sentido del escrito y siempre que no haya sonidos implicados, como en "repitición", "mesma" o "letor", que he dejado idénticos. 
Lo más lógico es que un escrito como este hubiera sido elaborado por el secretario, pues se trataba de un trámite obligatorio para los obispos, del cual luego tendrían que dar cuenta a sus superiores. En cuanto tal, era un documento a cargo del secretario. En efecto, desde Trento se esperaba que al menos una vez durante todo su mandato cada obispo visitara personalmente el estado de su diócesis, pues así podría remediar aquello que debía ser remediado y convocar luego a todos los párrocos a un sínodo, tal como hizo Alday. En ese contexto, el secretario debía llevar un registro que pudiera utilizarse luego para informar a instancias superiores sobre el estado de la diócesis. Por ejemplo, debía consignar cuántas leguas había caminado el obispo cada día, cuántas confesiones había escuchado, cuántas misas había celebrado. Con este material se podía hacer informes como la visita ad limina que se enviaba al papa?

Ahora bien, la voz que narra el viaje que aquí mencionamos no se limita a contar los hechos de la visita, sino que desliza constantemente comentarios y poemas alusivos al momento. Es alguien muy cercano al obispo, pues lo acompaña en todo momento e incluso hace bromas relacionados con él. Por ejemplo: "el medio día fue en el Asiento de las minas, que llaman La Dormida del Gobernador y ahora se puede llamar La Siesta del Obispo" (f. 3 v.), con lo que nos informa de paso que Alday tomó una siesta en dicho lugar. Juegos de palabras relativos a los topónimos son los más frecuentes en este escrito, como el siguiente: "Lunes 23 al mediodía, salimos, y caminando seis leguas, llegamos a la Quebrada del Negro, pero no salió el negro de la quebrada, que después nos vino a alcanzar adelante" (f. 6 v.).

Es interesante comprobar que le llaman la atención los nombres de los lugares y por ello se informa del origen de los topónimos, que explica en su relato algunas veces, como en el caso de un cerro llamado "el Bramador", del que averiguó que

[...] después que ha venido un temblor de tierra está un buen rato resonando o bramando y lo más admirable es que estando en silencio los demás cerros que tiene en circuito, solo un cerrito, que tiene en frente, cosa de una media legua, le responde y corresponde como que él solo lo entiende. Dios sabe lo que quieren decir. (ff. 8 r.-8 v.)

9 La visita ad limina de Alday se conserva en el Archivo Nacional Histórico de Santiago, Colección José Ignacio Víctor Eyzaguirre, vol. 36, ff. 3 r r.-39 r. 
Le gustó tanto el diálogo entre los cerros, que compuso una octava endecasílaba para el cerro bramador:

Dime, cerro locuaz, ¿qué estás hablando,

en el confín de Chile, tan parlero?

Después de los temblores rezongando,

no sé si indica algún fatal agüero,

que estás a todo el reino amenazando,

los enojos de Dios justiciero.

Porque la tierra sane en su clemencia,

voz del desierto, clamas: "penitencia". (f. 8 v.)

También se ríe de las dificultades del viaje, como una jornada en que no pudieron hacer misa porque no había hostias: "una laucha, a lo que dicen, de pelo rubio, se había comido las hostias, no sé con qué intención le vino la gana de comulgar" (f. 6 v.). En otros momentos del viaje, algo angustiosos, en que la comitiva se pierde de vista, el narrador se queda a solas con el prelado y le compone versos para divertirlo y consolarlo, diciendo que fue "la Musa" inquieta que interrumpió el relato de la visita.

No sabemos a quién se dirigía el escrito finalmente, pero podemos suponer que no saldría del estrecho círculo de los familiares que acompañaron al obispo en el viaje. Quizá la confianza entre el secretario y el obispo era tal que al regreso del viaje aquel le mostraría su versión del viaje con la finalidad de divertir al prelado, al mismo tiempo que le daba cuenta de los logros de la visita. Es poco probable que este texto se haya destinado a la publicación, pues la imagen que muestra del obispo es poco solemne. Quien se queda con el obispo en toda circunstancia es el secretario, por lo que nos muestra al obispo en una intimidad muy poco corriente, imposible de encontrar en la documentación oficial. En ese sentido, llama la atención que el secreto que el secretario está resguardando es el de la intimidad del obispo o su vida cotidiana, pues solo el secretario se enteraba de los detalles íntimos del día a día del prelado. Tales detalles, en el caso de que además fuera su confesor, incluían el secreto más íntimo de la conciencia. El secreto de la vida privada del obispo o al menos de lo que ocurría tras bambalinas mientras efectuaba la visita pastoral, no quedaba del todo bien resguardado, pues el secretario festeja con él al contar el viaje, mostrando a un obispo humano, que come, duerme y se cansa. Se trata de un secretario que, por su carácter de "familiar" del obispo, conoce lo más íntimo de su conciencia y de la intimidad de su día a día, pero lo disimula convenientemente en los 
documentos que debe escribir, y por ello el obispo Alday aparece ante la historiografía eclesiástica como un monumento sin fisuras, hierático ${ }^{\mathrm{Io}}$. En suma, este secretario nos permite acceder a una faceta del obispo que no podríamos conocer a partir de la documentación oficial, en la cual el secretario desaparece y solo queda su nombre, asociado a la firma que rubrica.

En contraste con el primer secretario, depositario del secreto de la intimidad, está el segundo secretario, que veremos a continuación, quien debía guardar otro tipo de secreto: el secreto público, aquel que podríamos llamar "político", en un contexto adverso en el que los pensamientos y las palabras del obispo debían ser resguardados de la luz que podía darles la imprenta.

\section{El secretario del obispo ante la expulsión de los jesuitas: dispositio, elocutio y secreto político}

El I2 de enero de 1772, poco tiempo después de haber tenido que ordenar la expulsión de su querida Compañía de Jesús del territorio chileno, el obispo Alday se encontraba en la Ciudad de los Reyes para participar del VI Concilio Limense, por orden del rey Carlos III. En un contexto adverso para aquellos obispos que, como él, estimaban a los jesuitas, Alday debió predicar una oración — sinónimo de plática o sermón — en la catedral de dicha ciudad, con motivo de la apertura del mencionado concilio. El contexto de la oración de Alday era muy tenso, pues el concilio respondía a una orden del rey Carlos III mediante la cual mandaba realizar reuniones provinciales en Perú y México, fundamentalmente con el objetivo de alinear a los obispos de las diócesis americanas después de la expulsión de la Compañía de Jesús de todos los reinos hispánicos, ocurrida recientemente en 1767 . En su real cédula del 2I de agosto de I769, conocida como Tomo regio (se puede leer completa en Silva), el rey ordenaba, entre otras cosas, asegurar el respeto irrestricto a la autoridad real y la extirpación definitiva de ciertas doctrinas "laxas" asociadas con los jesuitas. Pese a las órdenes de la Corona, muchos obispos seguían siendo afines a la Compañía: el propio Alday era conocido por su cercanía con ellos; en contraste, en la reunión de la catedral

Io Los principales biógrafos de Alday son Carlos Silva Cotapos y Javier González Echeñique.

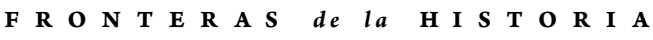


de Lima había obispos que rechazaban profundamente las doctrinas asociadas a los jesuitas, como fray Pedro Ángel Espiñeira, obispo de Concepción, quien asistió a la reunión y manifestó fehacientemente su rechazo. De este modo, era muy importante cuidar cada palabra dicha, sobre todo considerando que había además allí una serie de representantes del rey, incluido el propio virrey Amat, lo que da cuenta de la relevancia de la reunión ${ }^{\text {II }}$. Amat había sido gobernador de Chile hasta pocos años antes, por lo que sería interesante estudiar el reencuentro entre el obispo y el ahora virrey del Perú, en una instancia tan tensa.

La retórica sagrada, heredera de la retórica clásica, indicaba que todo buen orador debía adecuar su discurso al público que tenía en frente - es la adaequatio - . En este caso, Alday tuvo que considerar que estaba frente a varios promotores de medidas con las que él mismo no estaba de acuerdo, pero delante de los cuales no podía manifestar abiertamente su punto de vista, pues las mandaba el rey. El discurso, por lo tanto, debía ser muy prudente. Una vez terminada la oración, el maestrescuela de la catedral de Lima, doctor Esteban Joseph Gallegos, allí presente, decidió imprimirla en Lima, según indica en el prólogo al lector que incluyó en la edición impresa: "sensible al clamor universal y más que todo a la pasión que me imprimió una pieza perfecta en su género, elocuente, edificativa y llena de Sagrada Unción para penetrar los ánimos” (Alday, Oración). Sin embargo, al pedirle el texto al obispo, se enteró de que la pieza oratoria que tanto le había impresionado no provenía de un escrito acabado, ni Alday se la había aprendido de memoria; en definitiva, no existía un texto que pudiera ser llevado a las prensas ${ }^{12}$. Lo que Alday tenía, según le habría dicho al maestrescuela, era un conjunto de apuntes sueltos. Tras los ruegos e "importunidad" de Gallegos, Alday habría aceptado entregar los papeles "a su Secretario, que los ordenó y redujo fielmente a un cuerpo de lectura” (Alday, Oración). Lo interesante es que, al recibir el texto definitivo, le pareció a Gallegos que tenía "nuevos pensamientos y bellezas que no se me presentaron a la primera vista", lo que lo convenció de que "sería avaro para con el Orbe Literario si no concurriese a ministrarle un papel de tanta utilidad y provecho" (Alday, Oración). Desde el punto de vista de la retórica, lo que Gallegos pudo ver fue una dispositio y una elocutio que no había apreciado en la actio o versión

II Sobre el poder de la palabra predicada, véase Urrejola, El relox del púlpito.

I2 Sobre el proceso de producción de un sermón, considerando las etapas de producción, predicación e impresión, véase Urrejola, El relox del púlpito. 
oral, lo que, claramente, fue añadido por el secretario ${ }^{13}$. El maestrescuela ya conocía otra de las oraciones de Alday, que este había predicado en la apertura del sínodo diocesano de Santiago en 1763, lo que lo resolvió a publicar las dos juntas, "porque cada una de ellas solo tendrá el lugar debido, estando acompañada de la otra".

Como es evidente, lo que ha llegado a nuestras manos no es la oración que predicó Alday en I772, sino el texto ordenado, estructurado y embellecido por su secretario. Cabe preguntarse entonces ¿cuánto pudo haber agregado de su propia mano el secretario del obispo, si el texto hace exclamar al maestrescuela de la catedral de Lima que leyó allí pensamientos y bellezas que no había percibido antes? ¿Compuso y embelleció a solas el secretario la oración, a partir del borrador de Alday? ¿Fue guiado en su reescritura por el obispo, quien habría modificado lo dicho oralmente, pensando en la eternidad del scripta manent clásico? ¿Habrá matizado afirmaciones comprometedoras relativas al complejo momento político que se estaba viviendo luego de la expulsión de la Compañía de Jesús? Es de suponer que el texto final, que ordenaba y daba legibilidad a los apuntes de Alday, fuese revisado por este, ante lo cual cabe preguntarse: ¿lo habrá considerado el obispo copia suficientemente fiel de lo dicho de forma oral, o bien, al ver mejoradas sus propias palabras, habría decidido que ellas quedaran así para la posteridad, embellecidas por el ornato retórico que le dio el secretario o disimuladas convenientemente por él? En suma, ¿cuánto de la oración que leemos es de Alday y cuánto pudo haber añadido el secretario de su propia mano? El impreso no nos permite conocer nada de esto e incluso el mismo maestrescuela, al elogiar con orgullo americano la elocuencia de la oración, diluye las diferencias entre la oración inicial de Alday y la versión escrita por el secretario, diciendo: "yo, en honor de estos dominios, provoco a los lectores para que conmigo sientan que nuestra América Austral, con este ilustrísimo, no tiene qué envidiar a la Francia con sus Burdalues y Masillones”, en referencia a dos predicadores de moda que representaban el nuevo estilo neoclásico que terminó por desterrar la florida y a esas alturas agonizante tradición barroca. El nuevo estilo que tanto elogia Gallegos entraba además en plena consonancia con lo mandado por el rey Carlos III en su cédula de 16 de octubre de 1769 , en la que ordenaba:

I3 Hay múltiples manuales de retórica desde los orígenes de Occidente; no obstante, para la retórica propiamente cristiana se puede consultar a fray Luis de Granada, Los seis libros de la Rhetorica Eclesiastica. 
[...] que los sermones se reduzcan a la moral cristiana, para reprender los vicios, al dogma para enseñar la doctrina y principios de nuestra sagrada religión y la imitación de los santos, depuestas las alegorías y comparaciones odiosas que no estén fundadas en la verdad y, en fin, todo aquello que se llama circunstancias y suele reducirse a juegos de palabras vacías de sentido (cit. en Eyzaguirre I67-I75)

Con su estilo francés de moda, la oración de Alday se volvía sin duda más agradable a los ojos de los Borbones que si hubiera seguido la abigarrada oratoria barroca española que el propio Carlos III pretendía erradicar, pero cabe preguntarse: ¿era de Alday o del secretario esa pluma? He estudiado en otra parte que Alday no simpatizaba para nada con Carlos III. Por lo demás, en el VI Concilio se encargó de defender a los jesuitas con gran inteligencia, impidiendo que los presentes condenaran sus doctrinas (Urrejola, "Las lágrimas").

Incluso más: por el contenido de sus prédicas, el obispo Alday llegó a ser llamado "el Ambrosio de las Indias", en alusión al famoso predicador y doctor de la Iglesia san Ambrosio de Milán. Al respecto, surge la misma pregunta: jera él o su secretario quien merecía el apodo, en realidad? Imposible saberlo, pues tampoco sabemos si el secretario se limitaba a editar los apuntes después de la predicación o si también contribuía a confeccionar las prédicas desde antes de su versión oral; me refiero a las etapas iniciales de la elaboración retórica, llamadas inventio, dispositio y elocutio, que consistían, respectivamente, en hallar las ideas y argumentos más apropiados para persuadir, luego darles un ordenamiento argumental y finalmente embellecer las ideas y volverlas más expresivas en función del logro del objetivo persuasivo ${ }^{\mathrm{I} 4}$. Todas estas etapas se producían mucho antes de que el sermón fuera predicado, y requerían de todo el ingenio de quien componía el discurso.

No sabemos, en suma, si al predicar, Alday estaba desarrollando sus propias ideas o si seguía más bien las propuestas del secretario. En efecto, muchos de los sermones manuscritos de Alday que se conservan en el Archivo Nacional de Santiago de Chile no son autógrafos del obispo, sino que provienen de una caligrafía mucho más suave y ordenada que la suya, aunque suelen tener

I4 La oratoria sagrada siguió la tradición inaugurada por Grecia y sobre todo Roma sobre retórica forense. Un manual importante a este respecto es la Doctrina Christiana de san Agustín y sobre todo el punto cúlmine de la oratoria sagrada española, fray Luis de Granada en Los seis libros de la Rhetorica Eclesiastica. 
correcciones, tachaduras o precisiones que sí provienen de la mano de Alday ${ }^{15}$. Lo más probable, entonces, es que el obispo hubiese encargado a su secretario la composición de algunos sermones para luego predicarlos en la catedral, lo que perfectamente pudo repetirse en la oración de 1772. De este modo, ¿̨habrá sido solo una transcripción de ideas llevadas a un escrito definitivo por el secretario, o fue un sermón ideado inicialmente por el secretario y reescrito por él mismo a petición del maestrescuela, revisado y aprobado luego por el obispo para ser impreso? No tenemos cómo corroborar cuánto de los textos de Alday le pertenece a él y cuánto fue producido por el secretario, pero estamos hablando de varias plumas e incluso varias cabezas pensando los documentos producidos por el obispo. Lo que sí podemos intuir es que la mano que redactó la oración de Lima era consciente del peligro que corrían las palabras del obispo si eran inapropiadas y pasaban a la imprenta; por ello las embelleció y transformó al gusto de moda de la época. Las discusiones que se estaban dando entre los obispos eran indisimulables. No obstante, en el texto de Alday se logra pasar de forma tangencial por ellas, de forma muy astuta. Si consideramos que el virrey Amat estaba escuchando la oración, muy atento a la versión impresa, podemos suponer la importancia de la edición que realizaría el secretario, que no podía ir en contra de lo dicho por la Corona, a riesgo de violar el juramento de respeto al Real Patronato.

Respecto de la identidad de este secretario, al inicio de mis investigaciones yo pensaba que sería Blas de Vera, el sucesor de Joseph Gregorio Cabrera desde 1763 y que participó como secretario y notario en el sínodo diocesano. Sin embargo, la referencia que he encontrado sobre él lo señala dejando el cargo justo un año antes del VI Concilio limense de i772:

Vera, Blas de. Hijo de don Antonio de Vera y de dońa Rosa de Porras, nacido por 1736 y ordenado por el obispo Alday, el cual lo tenía de familiar, en Enero de 1760. Fue secretario de este prelado desde antes de I763 hasta I77I. En Julio de 1775 entró a servir a la parroquia de San Lázaro, recién fundada en la Cañada de Santiago, que había obtenido en concurso. En Febrero de 1782 se le trasladó a la parroquia de la Serena, ciudad de la cual fue cura y vicario hasta su muerte, que ocurrió en Santiago en junio de 1818. (Prieto del Río 703-704)

15 En un estudio del 2017 (Urrejola et al.) hicimos edición crítica de un autógrafo de Alday y pudimos establecer definitivamente cuál es su caligrafía. Por ello, resulta sencillo contrastar su letra con la de otros, como el caso mencionado arriba. 
Por lo tanto, no es posible saber si Blas de Vera alcanzó a relacionarse con la oración predicada por Alday en Lima en 1772 - por ejemplo, colaborando en su elaboración- o si fue él quien la editó al regreso del obispo a Chile. No he encontrado el nombre del secretario que lo sucedió en el cargo, por lo que no puedo asegurar que haya sido él quien trabajó el texto. Esto no es óbice para el análisis pues, como he señalado, más que una biografía me interesa una función. Así, es el trabajo del secretario más que su nombre el que aquí pongo de relieve.

En ese sentido, como cierre para este segundo caso de presencia del secretario en los escritos de Alday, retomemos la idea de secretario como depositario del secreto. Podemos especular que si el filojesuitismo de Alday era su "secreto" - a voces, pero secreto al fin y al cabo, en un contexto adverso en que el rey los había condenado al destierro-, al editar la oración que sería llevada a las prensas en un momento tan difícil como el de la reciente expulsión de la Compañía de Jesús, el secretario debió procurar que no quedaran indicios del polémico tema en un texto que sería revisado antes de que se autorizara su impresión. En efecto, el texto indica en su portada que cuenta "con las licencias necesarias" para imprimir, es decir, con los correspondientes permisos del gobierno secular y eclesiástico de Lima, según indicaba la legislación vigente ${ }^{16}$. Como era inevitable tener que referirse de alguna manera a lo que estaba ocurriendo, el escrito evidencia ciertas veladas alusiones que, sin embargo, podrían también haber sido enunciadas en cualquier otra reunión de obispos. Por ejemplo, dice que "no siempre asiste Dios en los Concilios de los hombres" (9), para referirse a la posibilidad de que los obispos reunidos pudieran equivocarse, como había sucedido en el pasado, cuando se habían tomado decisiones en los concilios que luego habían resultado perjudiciales para la Iglesia, por lo que debieron ser rectificadas tiempo después. En dichas ocasiones, dice, "ni el número, ni la sabiduría, ni la nobleza, ni la experiencia de los Obispos concurrentes vinculó a estas juntas el acierto o las preservó del error; en ellas eran hombres los que concurrían, y concurrían en su nombre [de Cristo], fiados de su poder, confiados de su autoridad, así, aunque tantos, no es mucho que errasen” (Io). Aunque podrían errar, dice que confía en que esta vez se reunirán "para edificar y no para destruir" (I5). Algunos, como el obispo de Concepción, Espiñeira, querían efectivamente aprovechar el concilio para destruir todo rastro de ideas jesuíticas y erradicarlas de la enseńanza, como ya vimos. A este respecto, se sabe que, 
durante el desarrollo del concilio, Alday impidió que los obispos condenaran las doctrinas de la Compañía de Jesús, afirmando que si el rey o el papa no lo habían ordenado explícitamente, los obispos no tenían la facultad para hacerlo (Millar), lo que, dicho sea de paso, era una argucia de Alday, pues el rey, si bien no mencionaba a la Compañía en el Tomo regio, claramente se refería a ella cuando decía que se debía erradicar las doctrinas laxas que estaban de moda.

El contexto en el que Alday pronunció su oración de apertura no podía ser más adverso para él. Hacía apenas cinco años que había sido obligado a expulsar a su querida Compañía de Jesús del reino de Chile, hecho que le había dolido profundamente. En el VI Concilio de 1772 debió luchar contra su par de Concepción, el obispo Espińeira, que pedía la condena formal de los autores de la Compañía. En ese escenario, ¿cuán enfático fue Alday en la versión oral de la oración de apertura que escucharon los asistentes al concilio? Al tener que editar el discurso para llevarlo a las prensas, ¿cuánto puso o quitó el secretario a la oración que efectivamente dijo Alday, si el impresor Gallegos dice que descubrió en el texto elementos que antes no había escuchado? ¿Fue esta edición del discurso oral una estrategia para proteger lo que podríamos llamar el "secreto político" del obispo, en la medida en que su filojesuitismo era conocido, pero en ese contexto era delicado expresarlo por escrito? En las actas del concilio no hay un detalle de las intervenciones de los obispos, lo que probablemente tuvo como finalidad protegerse de eventuales sanciones, como bien ha afirmado René Millar, aunque Espiñeira, apenas de regreso a su diócesis, publicó una carta pastoral (el 20 de noviembre de 1773) en la que condenaba furiosamente el probabilismo (Millar). Esto indica que las discusiones continuaron y se suma a que las actas del concilio nunca fueron aprobadas por el poder real. En ese sentido, no podemos saber si Alday dijo algo al respecto y luego lo quitó de la versión escrita, o si nunca se refirió al polémico tema. Como haya sido, el secretario supo guardar bien su secreto.

\section{A modo de cierre}

La presencia o la ausencia del secretario en los documentos episcopales nos lleva a reflexionar sobre aquellos personajes invisibles de la historia que con su trabajo contribuyeron al brillo de otros. En este caso, las huellas textuales nos hablan de un manejo letrado que se evidencia ampliamente en el uso de terminología jurídica y retórica, hasta el punto de volverse indiferenciable de lo que hubiera dicho o escrito el propio obispo. Más allá de esta característica 
propia de cualquier secretario, en el caso del obispo se trata de una mano que conociendo lo más íntimo de la conciencia, vislumbrado en confesión, anota, revisa, pule, cambia y, dado el caso, opina; es una mano que desaparece detrás de la figura imponente, hierática y formal del obispo, quien permanece mientras los secretarios pasan. Como depositarios del secreto, estos secretarios no pueden sino desaparecer tras la escritura, protegiendo tras ella el secreto del obispo: su vida íntima, cotidiana, lo más íntimo de su conciencia, pero también aquellas ideas que pudieran implicarlo en problemas políticos. Todo para dar una imagen sobria, oficial, del gobernador de la diócesis, imagen que ha trascendido en la historiografía eclesiástica asociada al obispo. El secretario permanece en su secreto y desaparece de la historia.

\section{8 \\ B I B L I O G R A F í A}

\section{FUENTES PRIMARIAS}

Alday, Manuel de. Oración que el llustrisimo Señor Doctor Don Manuel de Alday y Aspee, del Consejo de Su Majestad, Obispo de Santiago de Chile, dixo en esta Santa Iglesia Metropolitana de la Ciudad de los Reyes, la Dominica Infraoctava de la Epifania I2 de enero Enero de 1772. En la Apertura y Solemnidad con que se dio principio al Concilio Provincial, a que concurrió como uno de sus Sufragáneos. Sácala a luz el Doctor Don Esteva Joseph Gallegos, Maestre Escuela de dicha Santa Iglesia Metropolitana. Con las Licencias necesarias. Lima: Imprenta que está en la Casa de los Niños Huérfanos, 1772.

---. Relación del viaje que hizo con su comitiva el Ilustrísimo señor doctor don Manuel de Alday, dignisimo obispo de Santiago de Chile, en la primera visita de su obispado, desde el día 23 de abril de 1757 hasta el día 20 de noviembre del mismo año. Archivo Nacional Histórico de Chile, Colección José Ignacio Víctor Eyzaguirre, 1757, vol. 36, pieza I, 80 f., ff. I-29.

---. Synodo diocesana que celebró el Ilustríssimo Señor Doctor Don Manuel de Alday y Aspee [...]. Con Licencia en Lima, 1763, en la oficina de la Calle de la Encarnación.

González de Rosende, Antonio. Vida del Ilustrísimo y Excelentísimo Señor Don Juan de Palafox y Mendoza. Madrid, $167 \mathrm{I}$. 
Granada, Fray Luis de. "Retórica Eclesiástica”. 1576. Obras completas. Madrid: Fundación Universitaria Española, 1999, edición bilingüe latín-castellano.

Palafox, Juan de. "Direcciones pastorales o instrucción de la forma con que se ha de gobernar el Prelado en orden a Dios, a sí mismo, a su familia y súbditos”. 1646. Vida del Ilustrisimo y Excelentísimo Señor Don Juan de Palafox y Mendoza, de Antonio González de Rosende. Madrid, 1671 .

Pérez del Barrio, Gabriel. Dirección de secretarios de señores y las materias, cuidados y obligaciones que les tocan, con las virtudes que se han de precisar, estilo y orden del despacho y expediente, manejo de papeles de ministros, formularios de cartas, provisiones de oficios y un compendio en razón de acrecentar estado y hazienda, oficio de Contador y otras curiosidades que se declaran en la primera hoja. Por Gabriel Pérez del Barrio Angulo, Secretario del Marqués e los Vélez y Alcayde de la Fortaleza de su villa de Librilla. Dirigido al Marqués de Cañete don Juan Andrés Hurtado de Mendoza. Con privilegio, en Madrid, por Alonso Martín de Balboa, I6r3.

Sacrosanto y Ecuménico Concilio de Trento. Traducido al idioma castellano por don Ignacio López de Ayala. Agrégase el texto original corregido según la edición auténtica de Roma, publicada en 1564 . Madrid: Imprenta Real, 1785.

Torquemada, Antonio de. Manual de escribientes. "Coloquios satíricos. Jardín de flores curiosas”. Obras completas, vol. I, editado por Lina Rodríguez Cacho, Madrid: Turner, 1994.

\section{I. FU E N T ES SECUNDARIAS}

Agustín de Hipona, De Doctrina Christiana. Madrid: BAC, 1957.

Artola Renedo, Andoni. "El patrocinio intraclerical en el Antiguo Régimen: curias y familias episcopales de los arzobispos de Toledo (1755-1823)". Revista Hispana para el Análisis de Redes Sociales. vol. 21, n. ${ }^{\circ}$, 201 I, pp. 273-300. https://doi.org/10.5565/rev/redes.42 I

Dedieu, Jean Pierre. "El séquito de los obispos que pasaron a Indias en la primera mitad del siglo XVIII". La iglesia hispanoamericana de la Colonia a la República, editado por Lucrecia Enríquez y Rodolfo Aguirre. México: Pontificia Universidad Católica de Chile, Universidad Nacional Autónoma de México, 2008, pp. 203-230

Del Río, Elena. "La figura del secretario en la obra dramática de Lope de Vega”. Hispania, vol 85, n. ${ }^{\circ}$ I, 2002, pp. I2-21. https://doi.org/10.230741 41166

Enríquez, Lucrecia. De colonial a nacional. La carrera eclesiástica del clero secular chileno entre I650 y I8Io. México: Instituto Panamericano de Geografía e Historia, 2006. 
Eyzaguirre, José Ignacio Víctor. Historia política, eclesiástica y literaria de Chile. Valparaíso: Imprenta Europea de Ezquerra y Gil, I850.

Foucault, Michel. “¿Qué es un autor?”. De lenguaje y literatura. Barcelona: Paidós, I996, pp. 329-360.

García Gallo, Alfonso. "El consejo y los secretarios en el Gobierno de Indias en los siglos XV I y XVII". Revista Chilena de Historia del Derecho, n. ${ }^{\circ}$ II, I985, pp. 329-353.

Gómez, Margarita. “Secretarios del rey y escribanos de cámara en el Consejo de Indias: oficiales de la pluma para el gobierno de la monarquía”. Nuevo Mundo Mundos Nuevos, 2 de octubre del 2017. https://doi.org/10.4000/nuevomundo.71367.

González Echeñique, Javier. “Manuel de Alday y Aspée I712-1753-1788”. Episcopologio chileno I56I-I8IS, editado por Carlos Oviedo Cavada. Santiago de Chile: Ediciones Universidad Católica, 1992, vol. 2, 253-465.

Irigoyen López, Antonio. "Un obispado para la familia: Francisco Verdín Molina, prelado de Guadalajara y Valladolid en la segunda mitad del siglo XviI”. Historia Mexicana, vol. LVIII, n. ${ }^{\circ}$ 2, 2008 , pp. 557-594.

Latasa, Pilar. "La casa del obispo-virrey Palafox: familia y patronazgo. Un enfoque comparativo con la corte virreinal hispanoamericana". Palafox: Iglesia, cultura y Estado en el siglo XVII. Congreso Internacional IV Centenario del Nacimiento de Don Juan de Palafox y Mendoza, [celebrado en la Universidad de Navarra, durante los dias 13, I4 y is de abril de 2000]. Pamplona: Universidad de Navarra, 200I, pp. $201-228$.

López-Cordón Cortezo, María Victoria. "Secretarios y secretarías en la Edad Moderna: de las manos del príncipe a relojeros de la Monarquía”. Studia Histórica. Historia Moderna, vol. I5, 1996, pp. I07-I3I.

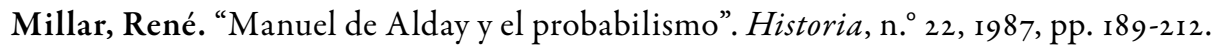

Prieto del Río, Luis Francisco (prbtro.). Diccionario biográfico del clero secular de Chile (I535-1818). Santiago de Chile: Imprenta Chile, 1922.

Rodríguez Cacho, Lina. "La frustración del humanista escribiente en el siglo Xvi: el caso de Antonio de Torquemada”. Criticón, n. ${ }^{44}$, 1988, pp. 6I-73.

Serrano Sánchez, Carmen. "Cartas al Papa: modelos epistolares en los manuales de correspondencia de los siglos XVI-XVII”. Via Spiritus, n. ${ }^{\circ}$ I8, 201 I, pp. I59-I82.

Silva Cotapos, Carlos. Don Manuel de Alday y Aspée, obispo de Santiago de Chile, I7I2-I788. Santiago de Chile: Imprenta Universitaria, 1917.

Urrejola, Bernarda. "Las lágrimas del obispo. Manuel de Alday ante la expulsión de los jesuitas del Reino de Chile". Revista SILEX, n. ${ }^{\circ}$, 20I8, pp. I2 I-I34. 
--.. El relox del púlpito. Nueva España en el contexto de la monarquía, según sermones de la época (I62I-I759). México: El Colegio de México, Universidad de Chile, 2017.

Urrejola, Bernarda, et al. "Edición y estudio de la Alegacía de méritos de Manuel de Alday y Aspée para optar a la canonjía doctoral de la Catedral de Santiago de Chile (1736)". Hipogrifo, vol. 5, 2017, pp. 519-565.

Villalba, Enrique y Emilio Torné. El nervio de la república. El oficio de escribano en el siglo de Oro. Madrid: Calambur, 20ıo, Colección Biblioteca Litterae 24. 